\title{
A study on ship automatic berthing with assistance of auxiliary devices
}

\author{
Van Luong Tran ${ }^{1}$ and Namkyun $\operatorname{Im}^{2}$ \\ ${ }^{I}$ The Faculty of Navigation, Vietnam Maritime University \\ ${ }^{2}$ The Faculty of Marine Transportation System, Mokpo National Maritime University
}

\begin{abstract}
The recent researches on the automatic berthing control problems have used various kinds of tools as a control method such as expert system, fuzzy logic controllers and artificial neural network (ANN). Among them, ANN has proved to be one of the most effective and attractive options. In a marine context, the berthing maneuver is a complicated procedure in which both human experience and intensive control operations are involved. Nowadays, in most cases of berthing operation, auxiliary devices are used to make the schedule safer and faster but none of above researches has taken into account. In this study, ANN is applied to design the controllers for automatic ship berthing using assistant devices such as bow thruster and tug. Using back-propagation algorithm, we trained ANN with set of teaching data to get a minimal error between output values and desired values of four control outputs including rudder, propeller revolution, bow thruster and tug. Then, computer simulations of automatic berthing were carried out to verify the effecttiveness of the system. The results of the simulations showed good performance for the proposed berthing control system.
\end{abstract}

KEY WORDS: Neural network; Ship automatic berthing; Bow thruster; Tugboat.

\section{NOMENCLATURE}

\begin{tabular}{|c|c|c|c|}
\hline ANN & Artificial Neural Network & $S$ & Distance from duct to water line \\
\hline$a_{j}$ & Activation value of a unit $\mathrm{j}$ in hidden layer & $S T A x / L$ & Local axial position \\
\hline \multirow[t]{2}{*}{$a_{H}$} & Ratio of lateral force induced on hull by & $T$ & Propeller thrust force \\
\hline & rudder to rudder normal force & $t_{P}$ & Effective thrust deduction factor \\
\hline$B$ & Breath of a ship & $W_{k i}$ & Weight on the link form unit $k$ to unit $j$ \\
\hline$D$ & Propeller diameter & $W_{j i}$ & Weight on the link form unit $j$ to unit $i$ \\
\hline Ds & Duct diameter & $X_{p}$ & Longitudinal force due to a propeller \\
\hline E & the sum of the squared errors & $X_{H}$ & $\mathrm{X}$-coodinate of center of lateral force induced \\
\hline$g$ & Gravity acceleration & & on hull by rudder interaction \\
\hline$I$ & Bottom immersion & $\beta$ & Sway angle of a ship \\
\hline$I_{z z}$ & Mass moment of inertia & $\rho$ & Density of water \\
\hline$J_{z z}$ & Added mass moment of inertia & $\xi, x$ & Advanced distance to berthing point form \\
\hline$L$ & Ship length between perpendiculars & & present ship's position \\
\hline$m_{x}$ & Added mass in surge direction & $\eta, y$ & Horizontal distance to berthing point form \\
\hline$m_{y}$ & Added mass in sway direction & & present ship's position \\
\hline$N$ & Propeller revolution per second & $u$ & Advance ship's speed \\
\hline
\end{tabular}

Corresponding author: Namkyun Im

e-mail:namkyun.im@mmu.ac.kr 


$\begin{array}{ll}v & \text { Lateral ship's speed } \\ r & \text { Ship heading turn rate } \\ \psi, P h i & \text { Ship heading angle } \\ \delta & \text { Rudder angle } \\ T f & \text { Output of bow thruster } \\ \text { Tug } & \text { Output of tugboat }\end{array}$

$B_{T} S_{T} \quad$ Bow thruster notch and stern thruster notch ordinate of the stern tugboat respectively (from 1 to 10)

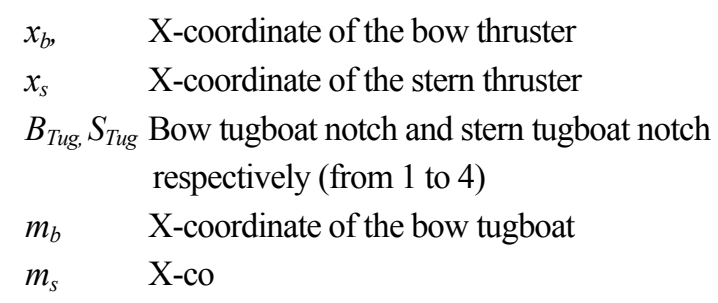

$x_{b}, \quad \mathrm{X}$-coordinate of the bow thruster

$X$-coordinate of the stern thruster

\section{INTRODUCTION}

Automatic berthing has been known as the one of the most difficult problems in ship control, since berthing operation could be characterized by the following: reduction of controllability at low speed, complicated and nonlinear differential equations of motion, effect of environmental disturbances and other problems. When a ship master maneuvers a ship in a harbor, usually he considers a lot of factors such as the ship's present speed, heading angle and the distance to the pier. Therefore the ships berthing control is considered one of multi input and multi output (MIMO) controller. Since late 1980s, research interests in automatic control have turned to developing the "intelligent control systems". Intelligent control can be classified into, but not limited to the following areas: expert or knowledge based systems, fuzzy logic controllers and NN based controllers.

Many researches have been carried out related to ship automatic berthing problems. Zhang, Hearn and Sen (1997) used a multivariable neural controller for automatic ship berthing and his proposed result can adapt neural controller's parameters by on-line evaluation of its performance accuracy, and hence its can cope with new situations. Recently, Im and Hasegawa (2001, 2002) suggested parallel neural controller on automatic berthing, later, he performed an application of ANN to automatic berthing using selective controller and got a successful result when the model ship started from any point around berthing areas.

In the marine berthing operation context, auxiliary devices such as side thrusters and tug boats have been widely used. According to the term "safety first" during ship operations, side thrusters and especially tugboats become very popular and essential. In this study we tried to improve the previous research by suggesting a new algorithm with an ANN controller that includes auxiliary devices such as bow thruster and tugboat. Two of the new controller-parameters, bow thruster and stern tugboat, are added simultaneously into basic controllers (rudder angle and rps) in the output layer. In the newly proposed system, the berthing procedure is divided into two stages. In the first stage a ship is automatically guided from the initial point to the first goal point. In the second stage, the ship is "pushed" to the final goal point with the help of side thruster and tug boat. The controller in the proposed system was designed to train the input data and it produces four outputs such as rudder angle, propeller revolution, bow thruster and tugboat's power. Finally numerical simulations were carried out to prove and verify the effecttiveness of the system.

\section{SHIP DYNAMIC MOTION}

A modern training ship named SAE NURI was adopted as a model (Fig. 1). The principal particulars are given in Table 1 and axes coordinates of the ship model are explicated in Fig. 2 respectively. In general, ship motions in the three vertical

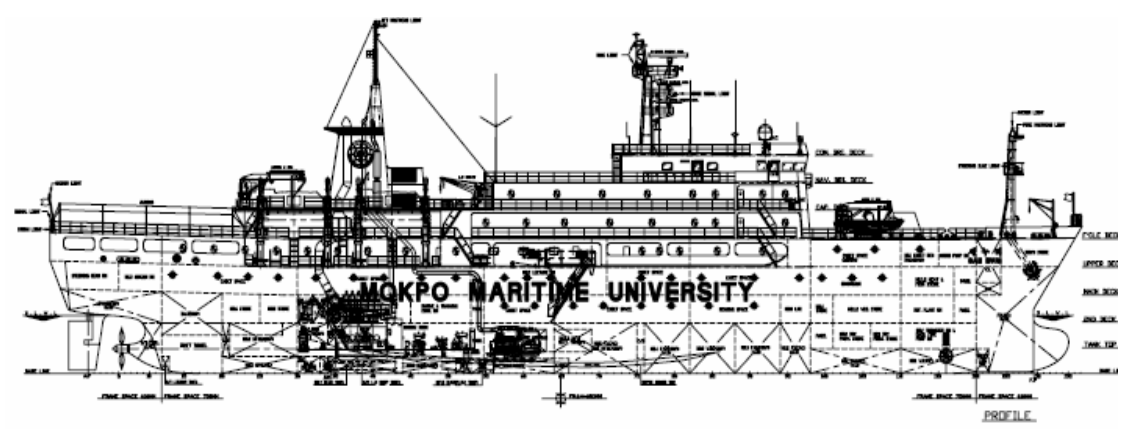

Fig. 1 General arrangement of ship model. 
degrees of freedom of heave, roll and pitch are assumed to be negligible with most maneuvering studies, so that the equation for ship's maneuvering motion can be expressed by the coupling motion of surge, sway, and yaw with respect to the right-handed coordinate system. Let $O-x_{o} y_{o} z_{o}$ be the earth-fixed coordinate and G-xyz be the body-fixed coordinate which is origin at the center of gravity.

Table 1 Principal particulars of the model ship.

\begin{tabular}{|c|c|}
\hline Type & Training ship \\
\hline LOA & $103[\mathrm{~m}]$ \\
\hline Lpp & $94[\mathrm{~m}]$ \\
\hline Beam & $15.6[\mathrm{~m}]$ \\
\hline Draft & $5.4[\mathrm{~m}]$ \\
\hline Thruster (bow) & $49,000 \mathrm{~N}$ \\
\hline
\end{tabular}

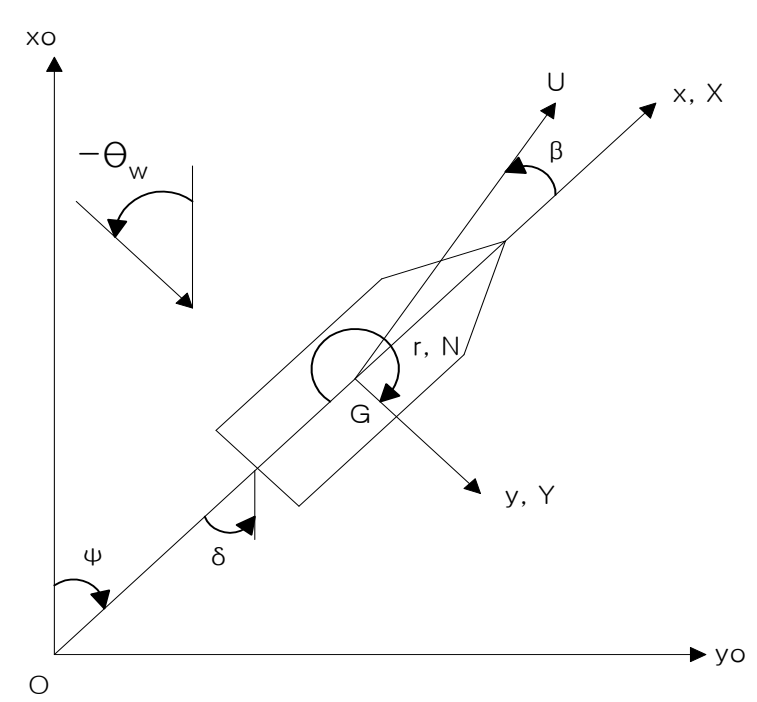

Fig. 2 Coordinate systems.

Nowadays the development of high technologies in navigation equipments provides us with various kinds of navigation aids such as a gyrocompass, AIS, GPS and RADAR. This makes navigators easily acquire more accurate ship states including heading, position, speed and yaw rate. In this simulation-based research, a neural controller is designed under assumption that these states can be undertaken on board ship. Many mathematical models about a ship motion have been proposed in previous researches. In this research, the model of Maneuvering Mathematical Modeling Group (Ogawa and Hamamoto, 1981) was used due to its reliability in expression of ship motion in the module-based-analysis. The surge, sway and yaw equations of motions of the ship, described with respect to the selected reference system, in which the total hydrodynamic forces and angular moment are split into separate parts. Those equations for three degree of freedom motion are displayed as follow:

$$
\left.\begin{array}{r}
\left(m+m_{x}\right) \dot{u}-\left(m+m_{y}\right) v r=X \\
\left(m+m_{y}\right) \dot{v}+\left(m+m_{x}\right) u r=Y \\
\left(I_{z z}+i_{z z}\right) \dot{r}=N
\end{array}\right\}
$$

where, $X$ and $Y$ are the external forces in the $x$ and $y$ direction, respectively. $N$ is the moment about $z$-axis through the center of gravity of ship. These external forces and moment are expressed in succession as Eq. (2): 


$$
\left.\begin{array}{r}
X=X_{H}+X_{P}+X_{R} \\
Y=Y_{H}+Y_{R}+Y_{T}+Y_{\text {Tug }} \\
N=N_{H}+N_{R}+N_{T}+N_{\text {Tug }}
\end{array}\right\}
$$

The subscription $H, P$ and $R$ represent the hull, propeller and rudder components, whilst $T$, Tug indicate bow thruster, tugboat components respectively. The hydrodynamic forces acting on the ship's hull are expressed in the form of a combination of linear and non-linear terms (Kijima, Nakiri and Furukawa, 1990) and described in the non-dimensional Eq. (3):

$$
\left.\begin{array}{c}
X_{H}=\frac{\rho}{2} L d U^{2}\left(X_{\beta r}^{\prime} \frac{r L}{U} \sin \beta+X_{u u}^{\prime} \cos ^{2} \beta\right) \\
Y_{H}=\frac{\rho}{2} L d U^{2}\left(\begin{array}{c}
Y_{\beta}^{\prime} \beta+Y_{r}^{\prime} \frac{r L}{U}+Y_{\beta \beta}^{\prime} \beta|\beta|+Y_{r r}^{\prime} \frac{r L}{U}\left|\frac{r L}{U}\right| \\
+Y_{\beta \beta r}^{\prime} \beta^{2} \frac{r L}{U}+Y_{\beta r r}^{\prime} \beta\left(\frac{r L}{U}\right)^{2}
\end{array}\right) \\
N_{H}=\frac{\rho}{2} L^{2} d U^{2}\left(\begin{array}{c}
\left.N_{\beta}^{\prime} \beta+N_{r}^{\prime} \frac{r L}{U}+N_{\beta \beta}^{\prime} \beta|\beta|+N_{r r}^{\prime} \frac{r L}{U}\left|\frac{r L}{U}\right|\right) \\
+N_{\beta \beta r}^{\prime} \beta^{2} \frac{r L}{U}+N_{\beta r r}^{\prime} \beta\left(\frac{r L}{U}\right)^{2}
\end{array}\right)
\end{array}\right\}
$$

Propeller thrust can be described simply in terms of the longitudinal force of the propeller $X_{P}$ as Eq. (4) below:

$$
\begin{gathered}
X_{P}=\left(1-t_{P}\right) T \\
T=\rho D^{4} n^{2} K_{T}(J)
\end{gathered}
$$

The hydrodynamic forces and angular moment generated by rudder can be expressed as Eq.(6) below:

$$
\left.\begin{array}{c}
\left.X_{R}=-\left(1-t_{R}\right) F_{N} \sin \delta\right) \\
\left.Y_{R}=-\left(1+a_{H}\right) F_{N} \cos \delta\right) \\
\left.N_{R}=-\left(x_{R}+a_{H} x_{H}\right) F_{N} \cos \delta\right)
\end{array}\right\}
$$

where

$$
F_{N}=\frac{\rho}{2} f_{a}(\Lambda) A_{R} U_{R}^{2} \sin \alpha_{R}
$$

Nowadays a transverse thruster, installed in a ship's bow and/or the stern, has become an essential piece of equipment on marine vehicles. It enables the ship to be maneuverable easily during its docking and berthing operations at low speed with tug assistance.

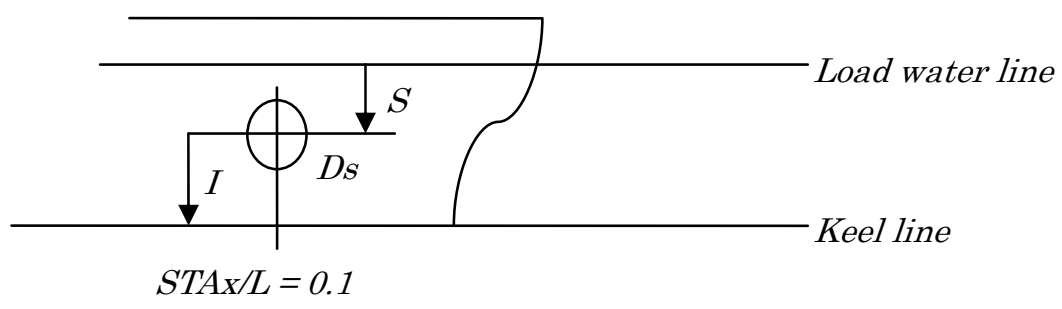

Fig. 3 Duct arrangement. 
This paper adopted Hawkins, et al. (1965) method to describe a side thruster in numerical simulation. The expression is given in Eq. (7).

$$
T=\left(5.12 * 10^{2}\right)\left(\frac{w_{0}^{2} \cdot L^{3} \cdot H}{M_{0}^{2}}\right)
$$

where $T$ is total lateral thrust (side force) of impeller and surfaces forces, $w_{o}$ is rate of turning; $L$, length on load water line, $m$; $H$, ship draft or net water head, $m$; $x$, distance of the bow thruster from forward peak and $M_{o}$ is rotation rate constant.

Let $T f(N)$ is bow thruster output, $T_{s}(N)$ is the stern output, then the forces in the $y$-axis and moments about the $z$-axis included by side thrusters are of the form Eq.(8):

$$
\begin{aligned}
& Y_{T}=T f \frac{B_{T}}{10}+T_{s} \frac{S_{T}}{10} \\
& N_{T}=T f x_{b} \frac{B_{T}}{10}+T_{s} x_{s} \frac{S_{T}}{10}
\end{aligned}
$$

Tugboats are highly maneuverable, and various propulsion systems have been developed to increase maneuverability and safety. A tugboat's power is typically stated by its engine's horsepower and its overall Bollard pull. The force and moment cause by tugboat can be calculated through its output power, let $\operatorname{Tug}_{b}(N)$ is tugboat thrust at ship's bow position, $\operatorname{Tug}_{s}(N)$ is tugboat thrust at ship's stern position, then the forces in the $y$-axis and moments about the $z$-axis induced by tugboats are of the form Eq. (9):

$$
\begin{aligned}
& Y_{T u g}=\operatorname{Tug}_{b} \frac{B_{T u g}}{4}+\operatorname{Tug}_{s} \frac{S_{T u g}}{4} \\
& N_{T u g}=\operatorname{Tug}_{b} m_{b} \frac{B_{T u g}}{4}+\operatorname{Tug}_{s} m_{s} \frac{S_{T u g}}{4}
\end{aligned}
$$

In this study, only bow thruster and tugboat (stern position) are set up, so the values of stern thruster force $\left(T_{s}\right)$ and tugboat at ship's position ( Tug $_{s}$ ) are defaulted as zero. The outputs of $T f$ and Tug (Fig. 3) are substituted into equations (8), (9) then their calculated forces and moments are also added to equation (2) to control the ship. In the process of making teaching data, both the value of bow thruster and a tugboat notch was controlled by manual maneuvering according to the model ship's situation. These notch values were set randomly from 1 10 (bow thruster) and 1 4 (tugboat) respectively.

\section{SHIP AUTOMATIC BERTHING CONTROL SYSTEM WITH ASSISTANCE OF AUXILIARY DEVICES}

\section{Artificial neural network design}

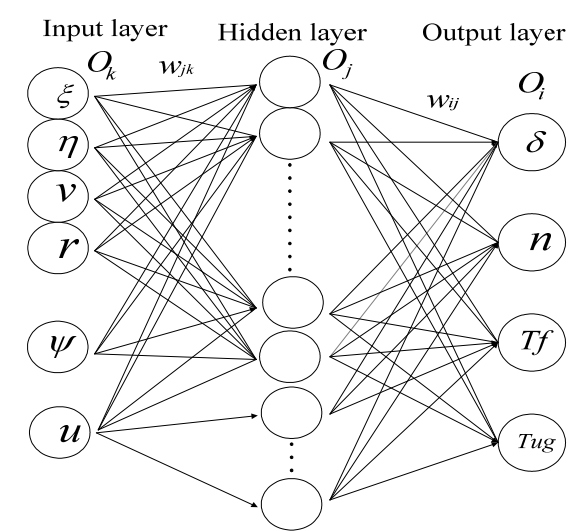

Fig. 4 The structure of neural network adopted as controller. 
Among the various available neural control schemes, the back-propagation neural controller is applied to process control problem. Back-propagation is a specific technique for implementing gradient descent in weight space for a multilayer feed forward network. The basic idea is to efficiently compute partial derivatives of an approximating function $f(w, x)$ realized by the network with respect to all the elements of the adjustable weight vector $w$ for a given value of input vector $x$. Herein lies the computational power of the back-propagation algorithm. In this study, the structure of neural network adopted as controller was built like Fig. 4, which is structured of 3 layers including input layer, output layer and hidden layer.

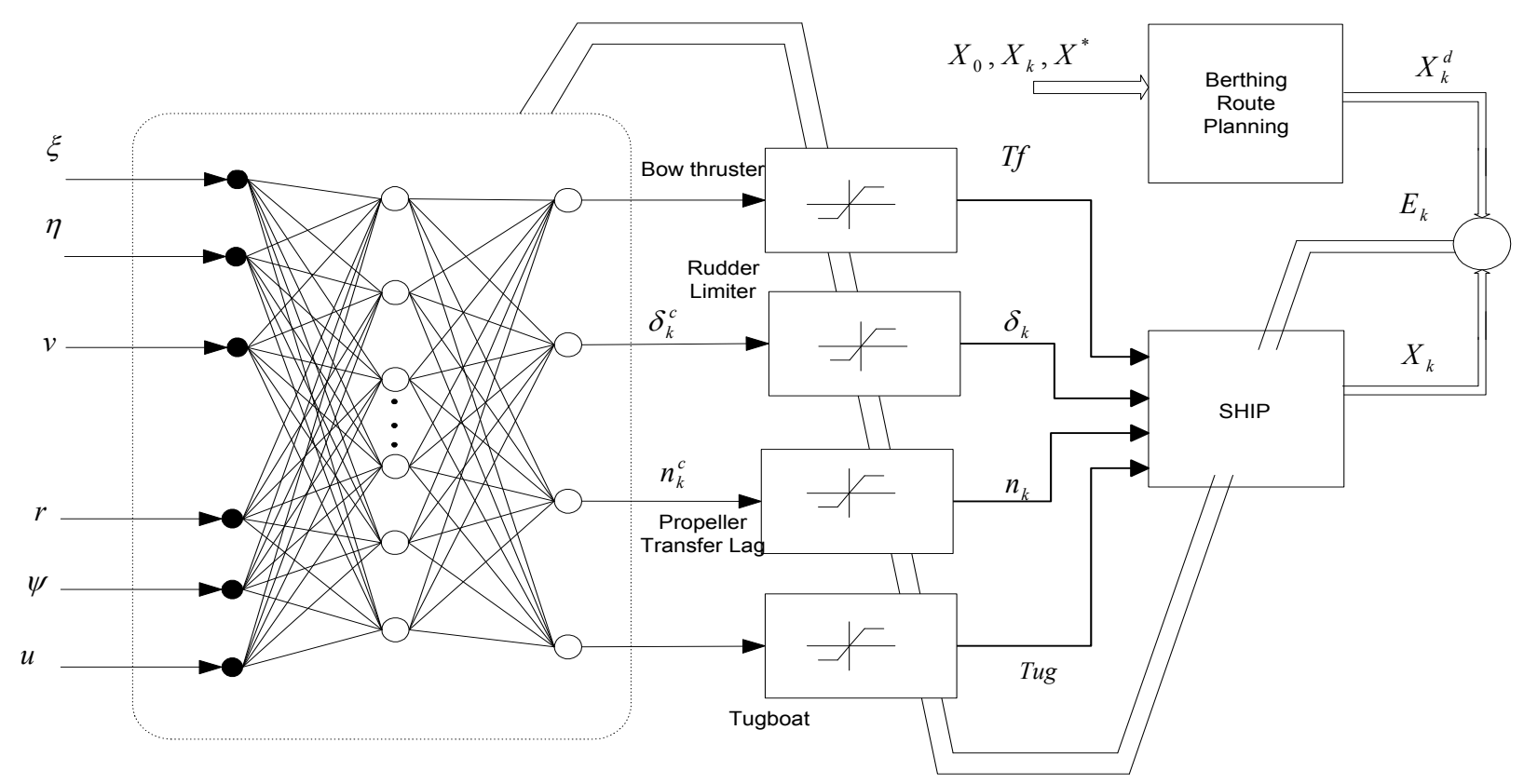

Fig. 5 MIMO neural control scheme for ship berthing.

The MIMO control system presented in Fig. 5 represents an extended version of the specialized learning strategy. The controller is constructed by a three-layer feed forward neural network. At the input item, 6 units are considered as follows: lateral and longitudinal distance $(\eta, \xi)$, advance and lateral speed $(u, v)$, turn rate $(r)$ and heading angle $(\psi)$. The output layer has 4 units consisted of rudder angle $(\delta)$, engine revolution $(n)$ and bow thruster and tugboat's output power (Tf, Tug). In the hidden layer, 17 neurons are set to recode (or to provide a representation for) the input, where $w_{i j}$ is used to indicate the weights between the hidden and the output layers, and $w_{j k}$ is used to represent the weights between the input and hidden layers. The subscripts $i, j, k$ identify a neural unit in the output, hidden and input layers respectively. The neural units contained in the hidden layer have the following non-linear function:

$$
O_{j}=\frac{e^{n e t_{j}}-e^{-n e t_{j}}}{e^{n e t_{j}}+e^{-n e t_{j}}}
$$

subject to:

$$
n e t_{j}=\sum_{k}\left(w_{j k} O_{k}\right)+\theta_{j}
$$

where $O_{j}$ represents the output of the $j$ th unit in the hidden layer, $n e t_{i}$ is the weighted sum of the output from the units in the input layer, and $\theta_{j}$ is the threshold value for the $j$ th unit in the hidden layer. Similarly, the satlins (net $_{i}$ ) function associated with units in the output layer is defined by Eq. (12) (13). Satlins is the symmetric saturating linear transfer function, it calculates a 
layer's output from its net input and values of $\left(\right.$ net $\left._{i}\right)$ truncated into the interval $[-1,1]$.

$$
O_{i}=\operatorname{satlins}\left(\text { net }_{i}\right)
$$

where :

$$
n e t_{i}=\sum_{j}\left(w_{i j} O_{j}\right)+\theta_{i}
$$

Here $O_{i}$ represents the output of the $i$ th unit in the output layer $\left(O_{i=1}=\delta, O_{i=2}=n, O_{i=3}=T f, O_{i=4}=\right.$ Tug). Herein, through the backward error compared with desired values, the network adjusts weights and bias ceaselessly during training process to satisfy Eq. (13). The aim of the study is to provide real-time control for automatic ship berthing. In order to train the model, back propagation was adopted; the variable learning rate method was used to minimize the time taken. The sum of square errors over the output values was used to evaluate efficiency of learning and it can be described by the following equation:

$$
E=1 / 2 \sum_{i}\left(T_{i}-s g\left(\sum_{j} w_{i j} s g\left(\sum_{k} w_{j k} I_{k}\right)\right)\right)^{2}
$$

where $E$ is the sum of the squared errors, $s g$ is sigmoid function, $T_{i}$ is the desired output, $w_{i j}$, $w_{j k}$ are weights on the link form unit $j$ to unit $i$ and $k$ to $j$. The training process is terminated when the equation (7) is satisfied in former fixed value. This paper has no ambition to explain fully about ANN theoretically design but concentrates on the concept of berthing and its results displayed by simulation procedure. To carry out numerical simulations, Matlab neural network toolbox was applied for its advantage and effect.

\section{Concept of berthing}

In this study, the automatic berthing operation is specifically divided into two parts based on the time of using auxiliary devices and the berthing phenomena context. According to previous researches, automatic berthing means that a ship stops near the berthing point within a speed of $0.2 \mathrm{~m} / \mathrm{s}$ and between angles of 250 270 degree of heading. The term "near berthing point" was not clearly defined. Nowadays, in practice, for the safety of berthing/unberthing most ship's masters require tugboats and the vessel's side thrusters (if any). This research suggests using bow thruster and tugboat in the proposed automatic berthing system where two new "goal points" are designed. Therefore two sub-controllers were built to solve the problem. The first ANN controller is designated to guide the ship from starting point to the first goal point. On the other hand, the main role of the second ANN controller is to "push" the ship toward the final goal point (mooring position) safely using the bow thruster and tug boat. As we mentioned in the first part, the newly added parameters in the control-unit (side thrusters and tugboats) will make the berthing operation safer and faster. This is the one of main points in this study that previous researches did not consider. The general structure concept of berthing context (Fig. 6) can be summarized as follows: firstly, the ship is controlled to the area 1 and ready for the berthing operation. The function of the first sub-controller is to control the ship from area 1 to the first goalpoint in area 2, area 2 is defined as a set of all first goal-points in which the ship has best condition (heading, speeds, and distance to the wharf...). From area 2, the ship will be controlled step by step to the quay by second sub-controller in which the using of side thruster and tugboat was included. Finally, the ship is put alongside and ready for mooring operation in safety.

One absolutely unsolved problem is found that when the ship approaches to the second goal point, its parameters are so sensitive and alterable. It is assumed that the non-linear threshold sigmoid function accepted the value of input parameters normalized between 0 and 1, but how these data is normalized to be suitable with the range scale of the threshold function? For example, when the ship navigates at the first stage, the advance speed is in scale of $-0.1 \sim 3 \mathrm{~m} / \mathrm{s}$ normalized equally with band 0 $\sim 1$ of threshold function. Then the ship approaches closely to the pier, advance speed is reduced around $-0.2 \sim 0.4 \mathrm{~m} / \mathrm{s}$. If the 
previous range of conversion is applied, it will cause a considerable error and the automatic berthing will finally get low accuracy. In order to solve that problem, the berthing operation is divided into 2 stages in which each one is equaled with its own converted range scale. In each stage, sub control system is built and trained to get independently result then finally, two above results can be associated in one unique system. Otherwise the concept of berthing is suitable with the real situation in which side thrusters and/or tug boats are used whenever the maneuverability of the ship is reduced in port area.

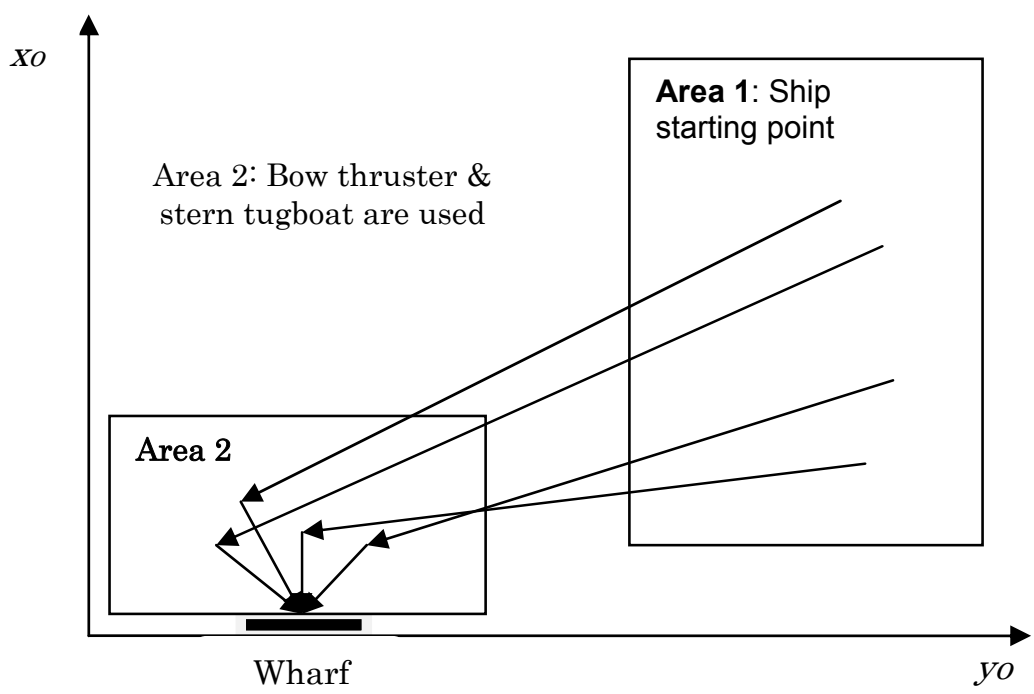

Fig. 6 General concept of berthing context.

\section{SIMULATION RESULTS}

\section{Teaching data}

In this part, numerical simulations were carried out to prove the above concept. First of all, teaching data sets were provided for the learning process, as mentioned in the section 3.2; two sets of teaching data were made simultaneously for separated stages. Teaching data is obtained by manual control for output control items such as propeller, rudder, bow thruster and stern tugboat. In the first stage, the ship is maneuvered into area 2 (Fig. 6) on the conditions that its velocity is less than $0.5 \mathrm{~m} / \mathrm{s}$, the heading is as parallel to the berth as possible and the value of the bow thruster/tugboat is assumed to be equal to zero. Fig. 7 shows the traces of teaching data and time history of parameters for first stage.

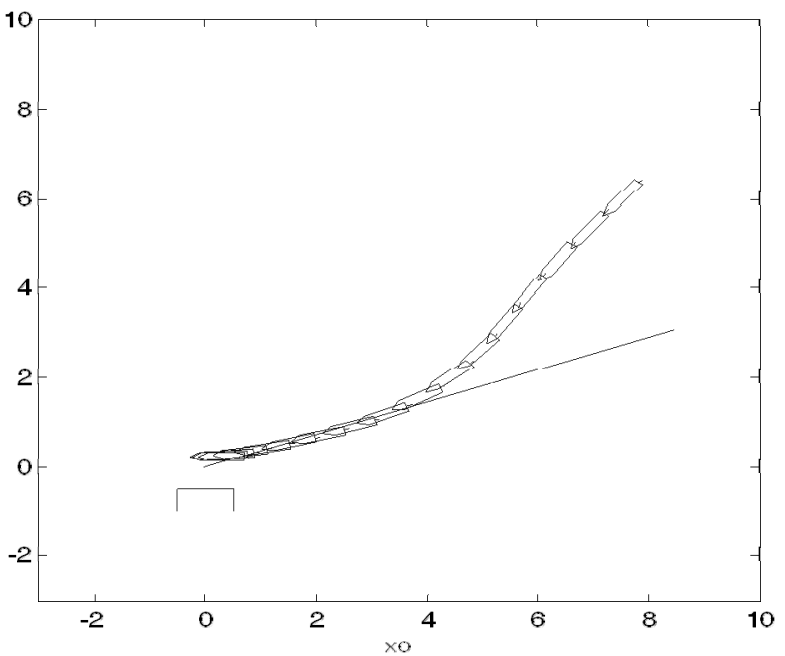

(a) One case of teaching data.

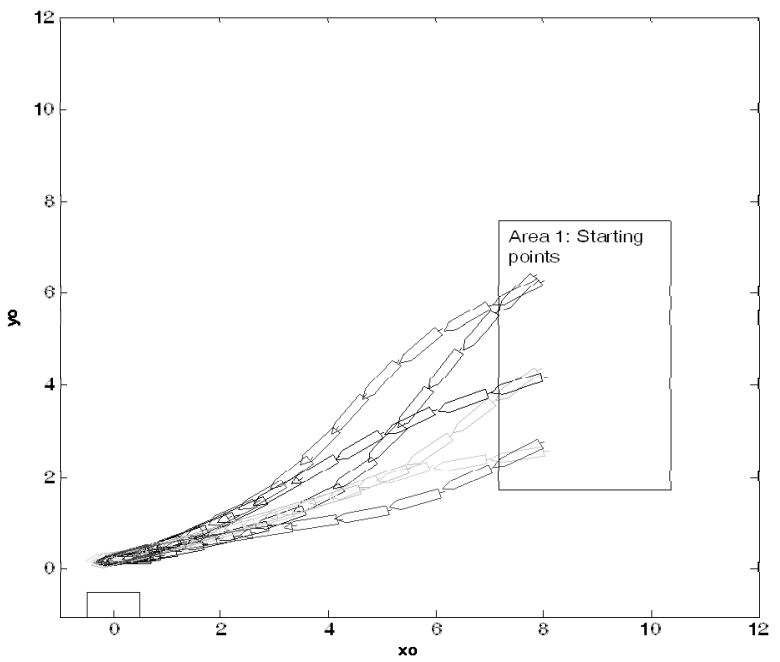

(b) Set of teaching data cover area 1 . 

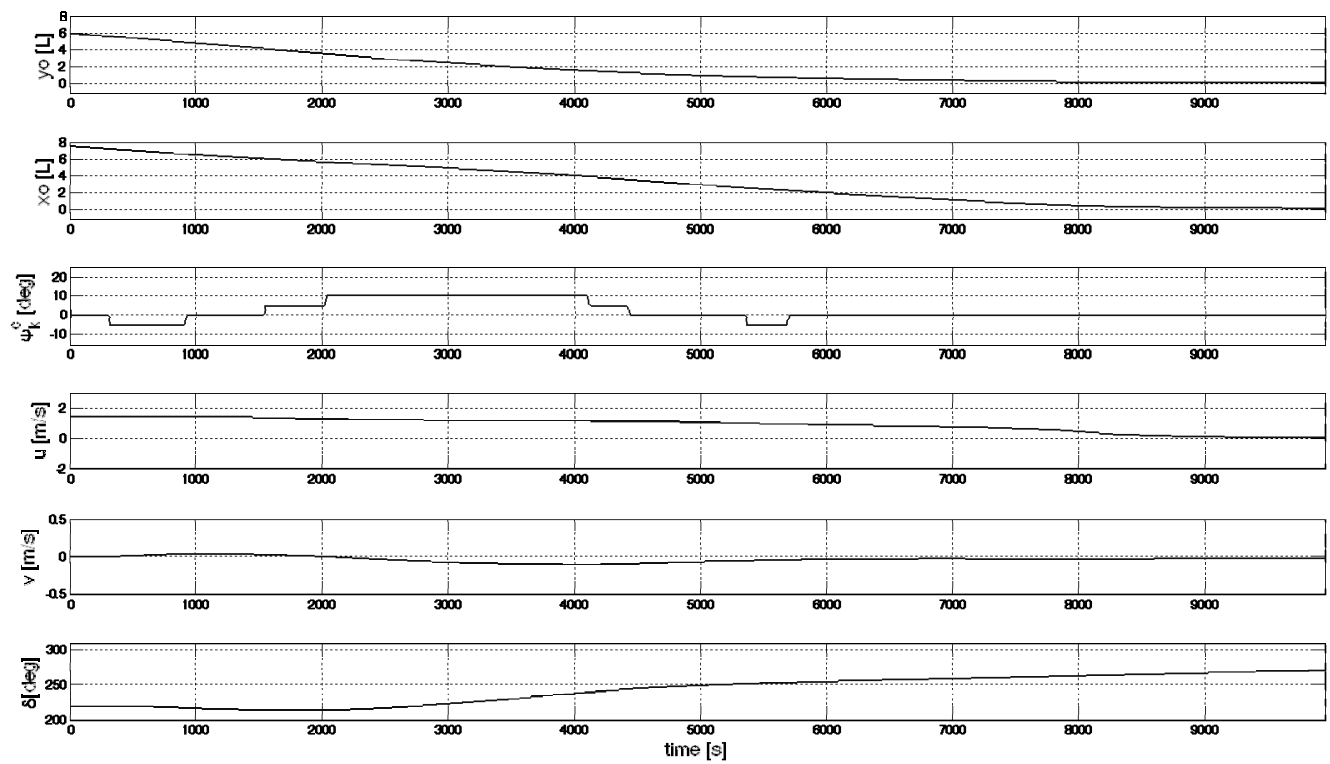

(c) Time history of one case (a).

Fig. 7 Teaching data provided for the first stage.

Another set of teaching data is also obtained in the second stage where ships velocity is assumed to be in the range of 0 to $0.5 \mathrm{~m} / \mathrm{s}$ without the effect of environmental disturbances. Fig. 8 shows several cases of teaching data for the second stage which covers area 2.
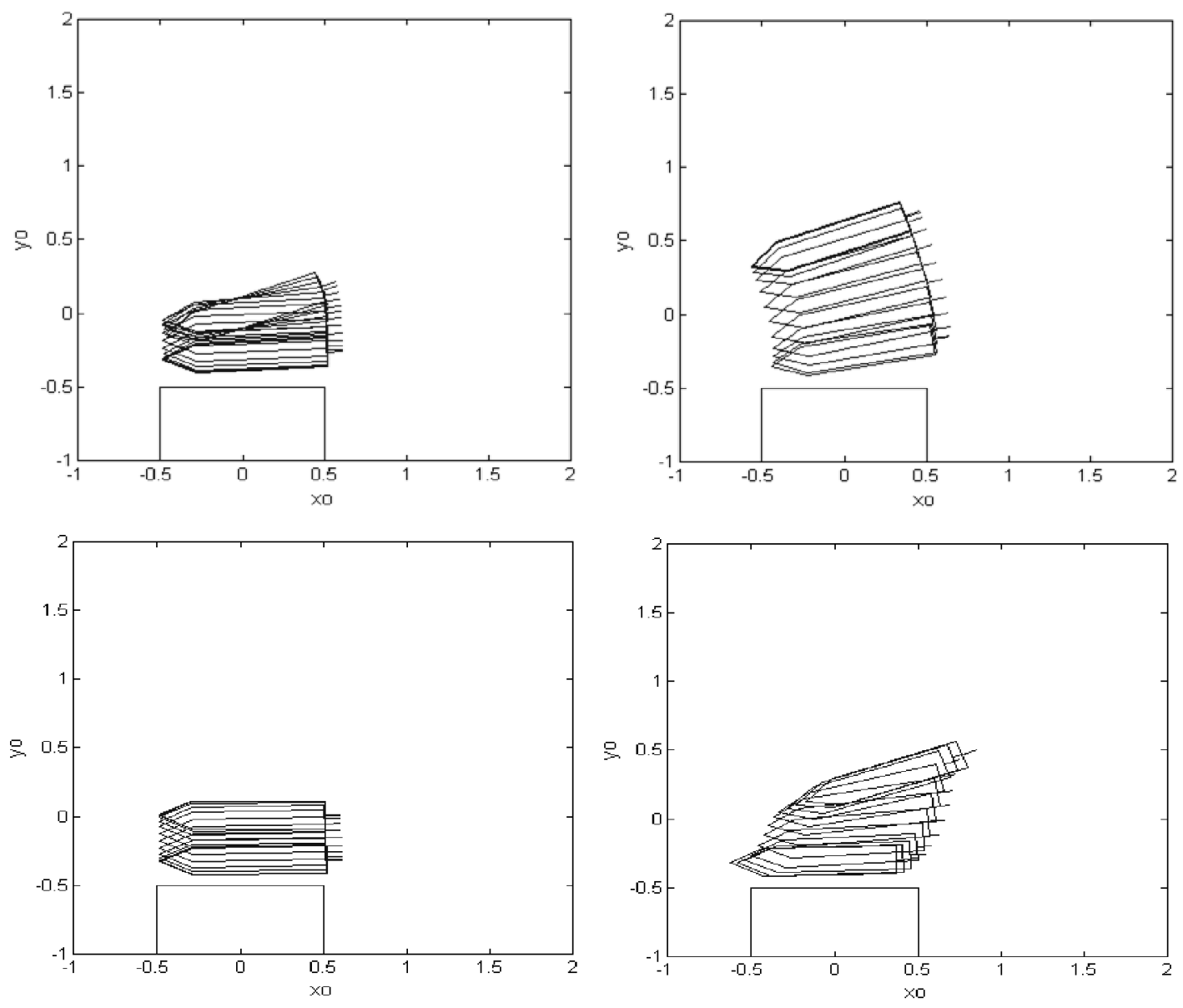

Fig. 8 Teaching data provided for the second stage. 
Fig. 9 and 10 show the successful simulation results for the first and second stage respectively in which the weights and biases were gained from the training process. Fig. 9 displays the simulation results for the first stage berthing. This process is almost similar to other researches. The results show the fact that even though the ships started from different starting conditions compared to the teaching data, they still reached the first goal point with reasonable parameters for the next step.

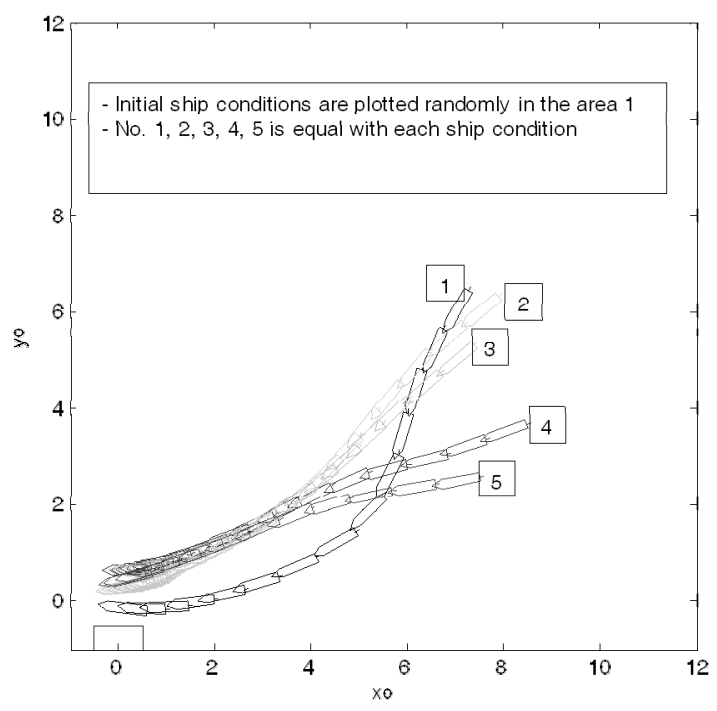

Fig. 9 Simulation results for the first stage.

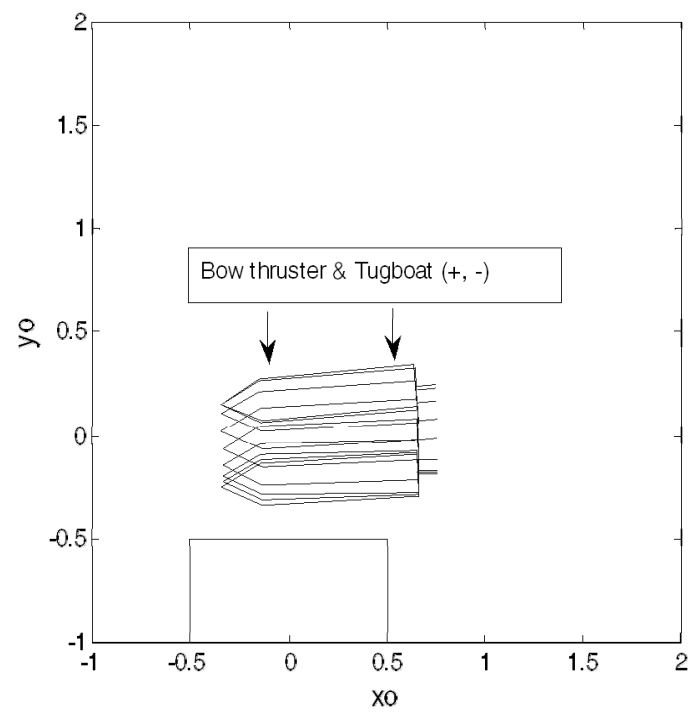

Fig. 10 Simulation result for the second stage of berthing.

The simulation results for the second stage is shown in Fig. 9 and 10 and the time history of the outcome parameters are displayed in Fig. 11 and 12 respectively. When having a look at parameters $T f$ (bow thruster) and Tug (tugboat) in real-time history (Fig. 12), it is found that the value output power of bow thruster and tugboat, at first, is negative value in order to gradually "push" the model ship in a lateral direction toward the final goal point. Therefore, the lateral speed $(v)$ gradually decreased to a negative value correlatively. Later both of them tenderly became positive to oppose the inertial movement of the model ship. The output power Tf and Tug in real-time history was almost same as the desired value in the teaching data set. Finally, the model ship reached the destination position with acceptable conditions. This would be the first trial study in which the adoption of side thruster and tugboat were proposed and simulated successfully.

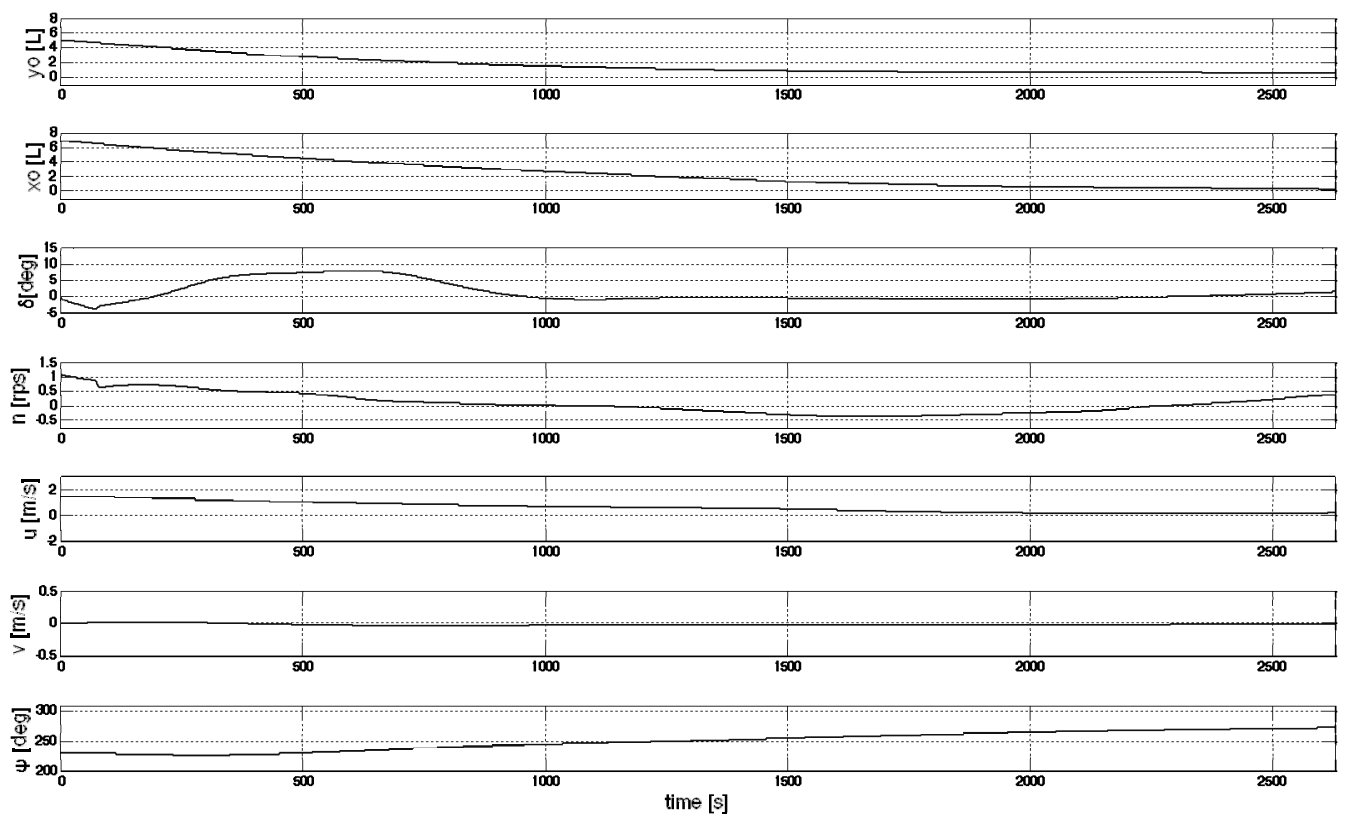

Fig. 11 Real-time of parameters used in first stage (case 4 Fig. 9). 

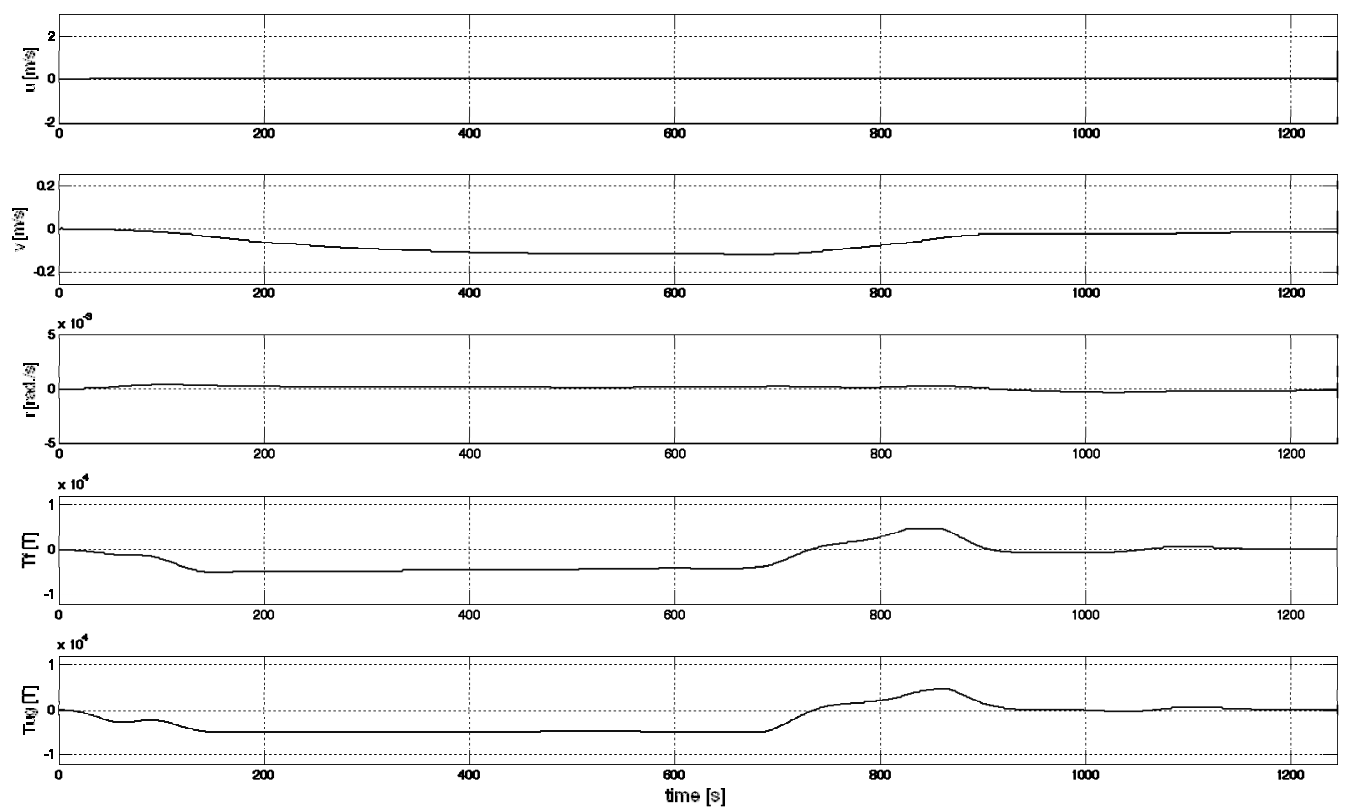

Fig. 12 Real-time of parameters used in second stage (case Fig. 10).

The last step is to combine two respective stages into unique controller. Generally speaking, this controller consists of 2 subcontrollers. Each sub-controller controls the model ship in its part and if the ship states meet the next fixed conditions, the other sub-system will be automatically activated. Due to the effectively working condition of side thrusters at low advanced velocity, the main ship's state factors such as: speed $(u)$, position $(x, y)$ are set as the meeting condition between 2 stages. These conditions are also originated from the practical experience of ship's master.

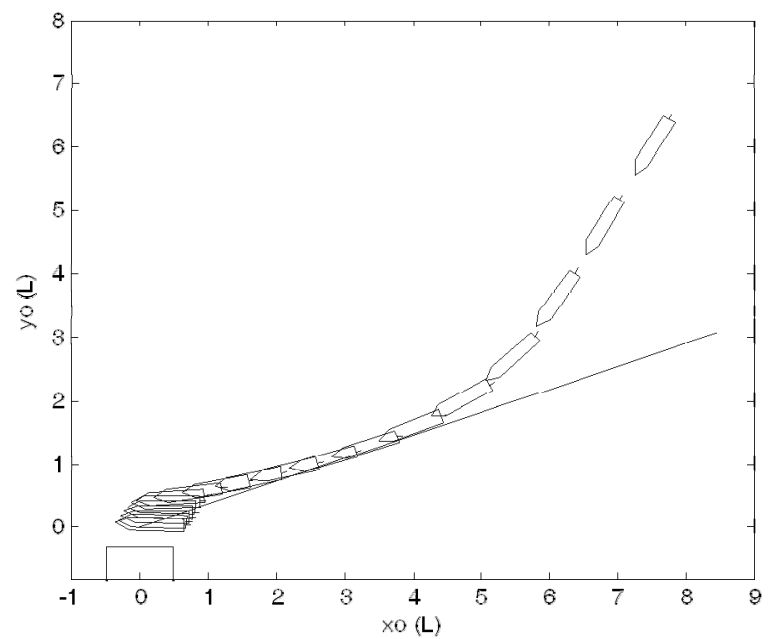

Fig. 13 Simulation result for the combination of 2 stages.

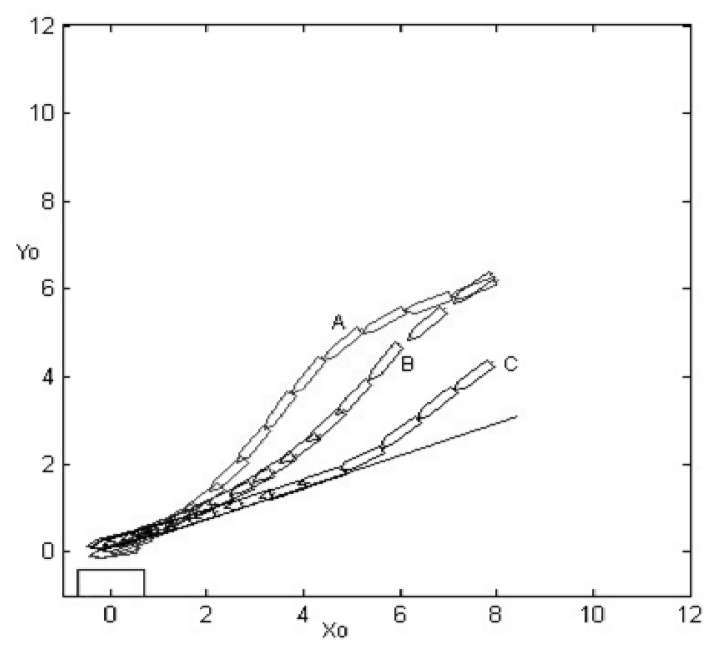

Fig. 14 Simulation result for the combination of 2 stages (with different starting condition).

Fig. 13 15 show the results of combinative simulation of automatic berthing for full process and its parameters time history respectively. When having a look at the time history of parameters in Fig. 15 (for once case), we can recognize that the berthing operation was divided into 2 stages clearly at the time around 1,500 (s). Concentrating on the changes of ship position (xo, yo) and speed $(u, v)$ between those stages, it was the key-point to keep the error of the process in minimum. Otherwise, the output powers of bow thruster and tugboat (Tf, Tug) at second stage firstly were in negative to "push" the ship laterality to the wharf and then they became positive to reduce the lateral speed until the ship stopped at the deigned position. These results were successfully described that the model ship reached to the pier in reasonable parameters for mooring operation with distance to the quay is about $0.15 \sim 0.3 \mathrm{~L}$. 

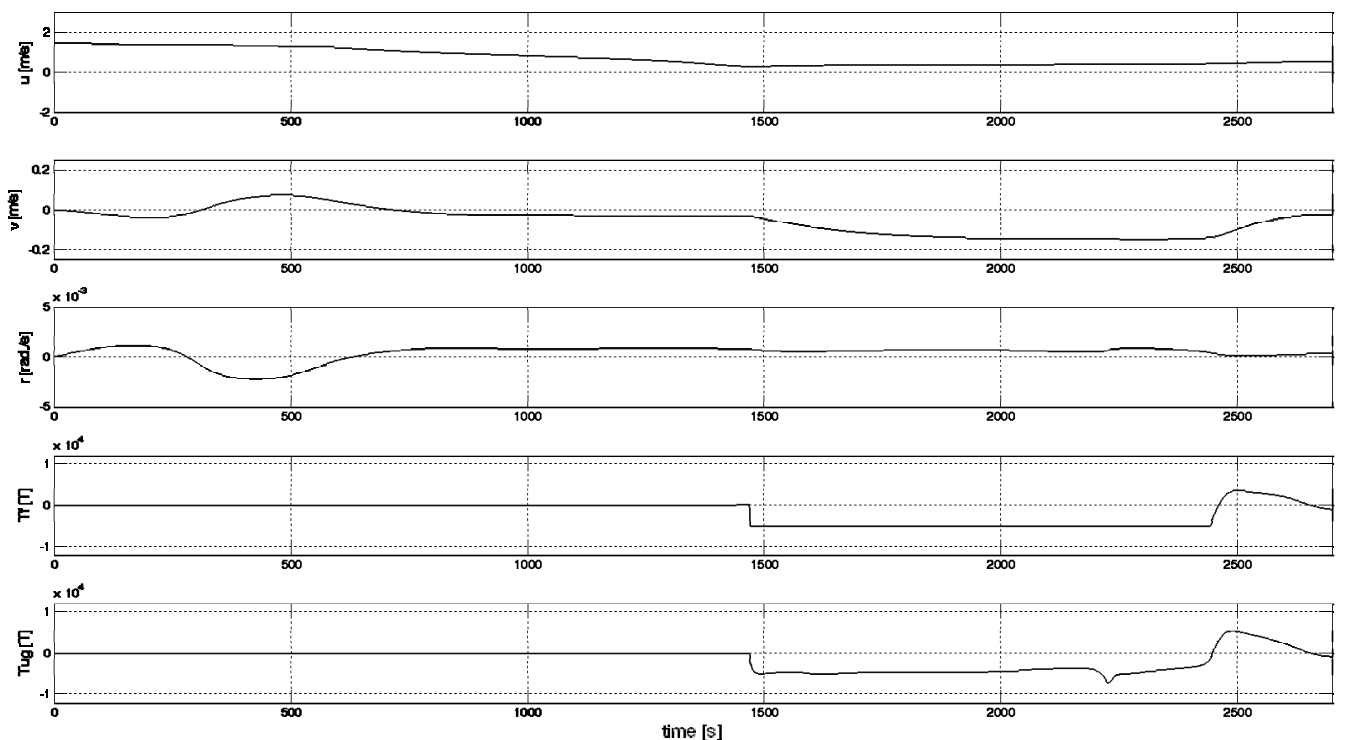

Fig. 15 Time history of parameters: Single case (Fig. 13).

\section{CONCLUSIONS}

This study suggested a new neural network controller system for automatic berthing control with the help of the above devices. The simulation results showed that the ship could automatically reach the designated goal point in a safe distance and heading angle.

The concept of automatic ship berthing controller was built based on the practical experience of qualified mariners. The merits of the proposed control strategy are summarized as below:

- This study proposed a new system for automatic berthing of a ship using ANN with the help of auxiliary devices such as side thruster and tugboat. The designed controller proved that it can integrally handle the previously mentioned difficult problems in ship berthing operations.

- In this study, ship berthing context was divided into two stages where each controller was designed to guide the ship in its area respectively.

- Numerical simulations were carried out and their results demonstrated that the controller built for the proposed berthing system verified its effectiveness.

- The results of this study have been based on a standard ship model. Future work will validate the applicability of the proposed neural controller for different ship models under disturbances of environmental conditions. It is believed that the realization of these advantages will contribute to the enhancement of marine safety by providing some effective, reliable and advisory tools for the captains or pilots in berthing operations.

\section{REFERENCES}

Hawkins, S. et al., 1965. The use of maneuvering propulsion devices on merchant ships. Robert Taggart, Inc. Report RT8518, Contract MA-3293.

Im, N.K. and Hasegawa, K., 2001. A study on automatic ship berthing using parallel neural controller. Journal of the Kansai Society of Naval Architects, Japan, 236, pp.65-70.

Im, N.K. and Hasegawa, K., 2002. Motion identification using neural networks and its application to automatic ship berthing under wind. Journal of Ship \& Ocean Technology, 6(1), pp.16-26.

Kijima , K., Nakiri ,Y. and Furukawa, Y., 1990. On the maneuvering performance of a ship with the parameter of loading condition. Journal of the Society of Naval Architects of Japan, 168(2), pp.141-148.

Ogawa, A. and Hamamoto, M., 1981. Principle of the mathematical model of ship maneuverability. Proceedings of the $3 r d$ symposium on the ship maneuverability. Japan, Society of Naval Architects of Japan. pp.9-26.

Zhang, Y., Hearn, G.E. and Sen, P., 1997. A multivariable neural controller for automatic ship berthing. Control System Magazine, IEEE, 17(4), pp.31-45. 